\title{
Revisão Sistemática sobre Letramento Digital na Formação de Professores: desafios e possibilidades
}

\author{
Carine Rodrigues da Costa ${ }^{1,2}$, Rousejanny da Silva Ferreira ${ }^{2}$ \\ ${ }^{1}$ Instituto Federal de Educação, Ciência e Tecnologia de Mato Grosso (IFMT) \\ Barra do Garças, MT - Brazil \\ ${ }^{2}$ Instituto Federal de Educação, Ciência e Tecnologia de Goiás (IFG) \\ Senador Canedo, GO - Brazil \\ carine.rodrigues@bag.ifmt.edu.br, rousejanny.ferreira@ifg.edu.br

\begin{abstract}
This Systematic Literature Review (SLR) investigated research developed in the last five years (2015 to 2019) in Brazil concerning the technologies and teaching methodologies used to train teachers in digital literacy. Eighty-five papers were found and only eight were selected for analysis. The main technologies found were the use of links, images, audio, videos, social networks and applications for mobile devices. The most used teaching methodologies were B-learning and M-learning. It was concluded that the union of teaching methodologies and technologies applied in digital literacy to training teachers can reflect on the success of learning and
\end{abstract} \\ motivation to apply in their daily routine.
}

Resumo. Esta Revisão Sistemática da Literatura (RSL) investigou pesquisas desenvolvidas nos últimos cinco anos (2015 a 2019) no Brasil a respeito das tecnologias e metodologias de ensino utilizadas para formação de docentes em letramento digital. Foram achados 85 trabalhos e selecionados somente oito para análise. As principais tecnologias encontradas foram uso de links, imagens, áudios, vídeos, redes sociais e aplicativos para dispositivos móveis. As metodologias de ensino mais utilizadas foram B-learning e M-learning. Concluiu-se que a união de metodologias de ensino e tecnologias aplicadas na formação em letramento digital para os docentes podem refletir no sucesso do aprendizado e motivação para que os professores apliquem em sua rotina diária.

\section{Introdução}

Os avanços nas Tecnologias de Informação e Comunicação (TICs) trazem constantemente novos desafios na educação, e por conseguinte aos docentes, na medida em que muitos alunos hoje nascem imersos no meio digital, os chamados "nativos digitais". Dessa forma, é fundamental aprender novas formas de ensinar com maior eficiência, e fazer com que ocorra efetivamente o processo de aquisição de conhecimento. Para atender essa demanda de alunos nos processos de ensinoaprendizagem é essencial que o professor tenha domínio das tecnologias voltadas à educação e seja um letrado digital, e um caminho é a Formação Inicial e/ou Continuada.

Sobre os estudos de letramento digital, Moura, Carvalho e Mion (2019) identificaram estudos nacionais e internacionais sobre o tema na formação de professores, sintetizando os objetivos buscados pelos pesquisadores, por meio de 
revisão sistemática no período de 2014 a 2018. O trabalho teve duas análises em seus achados, que foram: percepções, concepções, crenças e sentidos do letramento digital nos processos formativos dos professores; e usos e apropriações das tecnologias digitais para o desenvolvimento do letramento no âmbito da formação. Concluíram que existem muitas possibilidades para executar formação inicial e/ou continuada e que a quantidade de publicações sobre este tema é considerada pequena, diante das necessidades atuais dos docentes.

Moura (2019) identificou produções científicas brasileiras (teses e dissertações) a respeito do letramento digital na formação de professores, no período de 2010 a 2018, com o objetivo de sistematizar os objetivos de pesquisa encontrados, as perspectivas de letramento digital, os procedimentos e instrumentos metodológicos utilizados e resultados encontrados. Foram selecionados 37 trabalhos, que comprovadamente mostraram que o uso das tecnologias trouxe melhorias nos processos de leitura e escrita, resultando na alta demanda e possibilidades existentes para aplicabilidade de letramento digital na formação de docentes.

Dessa forma, a pesquisa se justifica devido à necessidade de compreender a relação entre tecnologias e metodologias de ensino para formação de professores em letramento digital, para complementar as duas revisões sistemáticas encontradas. Destarte, o objetivo deste trabalho foi investigar pesquisas desenvolvidas nos últimos cinco anos (2015 a 2019) no Brasil por meio de Revisão Sistemática da Literatura (RSL) sobre as tecnologias e metodologias de ensino utilizadas para formação de docentes voltadas ao letramento digital, para compreender quais ferramentas e metodologias utilizadas para formação em letramento digital utilizadas em conjunto que obtiveram maior e menor sucesso em sua aplicação, i.e., identificar as contribuições e desafios para a melhoria da qualidade de ensino, com o intuito de relacioná-las e propor novas possibilidades para a prática do letramento digital.

\section{Letramento Digital e Formação de Professores}

A RSL de Pinto, Boscarioli e Capelli (2018) investigou a conceituação do termo letramento digital no período de 2004 a 2018, onde encontraram os termos "letramento digital” e "alfabetização digital” que são termos sinônimos criados no Brasil, advindos do termo em inglês "digital literacy”. Foram apresentadas várias definições, e entenderam que letramento digital refere-se às competências necessárias para utilização de TICs em situações cotidianas.

A pessoa letrada detém a capacidade de ler e escrever, compreender, questionar. A leitura e escrita estão em diversos meios, inclusive o digital. Portanto, o letramento digital envolve o domínio das tecnologias digitais, mas que não seja mecanizado a ponto de “[...] ser um mero apertador de botões [...]" (VALENTE, 2007, p.12).

Dentre os benefícios do letramento digital, enquadram-se: professores mais preparados para elaborar aulas e materiais mais interessantes, uso correto dos canais de comunicação (seguros com informações confiáveis), produção de conteúdos, participação e engajamento em comunidades e redes, pessoas autônomas e racionais, inclusão social (WILSON et. al, 2013, p. 20). Todavia, muitas vezes, essa qualificação em letramento digital não é alcançada de modo autodidata no ambiente escolar.

Ademais, a formação de professores é realizada em duas modalidades: a formação inicial e a formação continuada. A formação inicial ocorre nas disciplinas teóricas e práticas pertencentes aos currículos dos cursos de licenciatura. A formação 
continuada é realizada após a conclusão de seu curso superior, e pode ser realizada de diversas formas, como cursos presenciais, à distância, semipresenciais, aperfeiçoamento, especialização, mestrado, doutorado, eventos científicos, etc. Em relação às políticas públicas, o Plano Nacional de Educação (PNE 2014-2024) promete ampliar a oferta de formação inicial e continuada para os profissionais da educação e prevê em sua meta sete "fomentar a qualidade da educação básica em todas as etapas e modalidades[...]”. Essa meta prevê em seus subitens a inserção e uso das TICs, que consistem em incentivar e prover o desenvolvimento e uso de tecnologias educacionais nos níveis básicos de educação, incentivar práticas pedagógicas e fornecer infraestrutura de recursos tecnológicos (BRASIL, 2014, p. 61).

Como visto, existem políticas públicas que exigem e incentivam o uso das TICs da formação docente. Do mesmo modo, diversas tecnologias estão na rotina da escola, trazendo diversos desafios aos docentes, gestores, e todo o ambiente escolar. Diante desses fatores, é evidente a necessidade da realização de pesquisas que envolvam estes temas de maneira prática, bem como a ampliação de políticas públicas que forneçam apoio à toda comunidade acadêmica.

\section{Método}

Para esta pesquisa foi adotado o processo de Revisão Sistemática da Literatura (RSL) baseado em Kitchenham e Charters (2007), conduzido em três etapas: planejamento, condução e relatório. A primeira etapa envolve as seguintes atividades: i) definição do(s) objetivo(s); ii) definição do protocolo da pesquisa que envolve a criação das questões de pesquisa, a definição da estratégia de busca de trabalhos primários, a definição das fontes de busca, a definição da string de busca e por fim, a definição dos critérios de inclusão e exclusão de trabalhos primários.

$\mathrm{Na}$ etapa de planejamento, os objetivos correspondem a investigar pesquisas desenvolvidas nos últimos cinco anos (2015 a 2019) sobre as tecnologias e metodologias de ensino utilizadas para formação de docentes voltadas ao letramento digital. Foram delimitadas três questões de pesquisa: Q1. Quais são as tecnologias que dão suporte às metodologias para o ensino de letramento digital na formação de docentes (inicial/continuada)?; Q2. Quais metodologias de ensino têm sido utilizadas para formação (inicial/continuada) de docentes em letramento digital?; Q3. Quais tecnologias e metodologias de ensino utilizadas em conjunto para formação de docentes (inicial/continuada) em letramento digital que obtiveram maior e menor sucesso em sua aplicação, i.e., quais contribuíram e quais não contribuíram para a melhoria da qualidade de ensino? As questões Q1 e Q2 formam um aparato suficiente para responder a questão principal desta pesquisa, a Q3.

A pesquisa foi realizada no dia 22/05/2020, e de acordo com as especificidades de cada base, as bases utilizadas e suas respectivas strings de busca foram: Portal de Periódicos da Capes (busca geral) e Biblioteca Digital Brasileira de Teses e Dissertações (("Letramento digital” OR "literacia digital" OR "alfabetização digital") AND (“formação docente” OR “formação de professor*” OR “formação de educador*”) AND (tecnologia* OR TIC OR TDIC OR software* OR aplicativo*) AND ("metodologia* de ensino" OR método*)); Scielo ((Letramento\$ OR literacia OR alfabetização AND digita\$) AND formação AND (docente\$ OR professor\$ OR educador\$) AND tecnologia\$ OR TIC OR TDIC OR software\$ OR aplicativo\$ AND metodo\$), e buscas manuais. Para a avaliação e seleção dos estudos encontrados, foram delimitados critérios de inclusão e exclusão, descritos no Quadro 1. 
Quadro 1: Critérios de inclusão e exclusão. Fonte: Feito pelos autores (2020).

\begin{tabular}{|c|c|}
\hline Critérios de inclusão & Critérios de exclusão \\
\hline $\begin{array}{l}\text { I1. Estudos disponíveis nas bases de dados } \\
\text { selecionadas/consultadas; } \\
\text { I2. A publicação está disponibilizada por } \\
\text { completo. } \\
\text { I3. Pesquisas publicadas nos últimos cinco anos } \\
\text { (2015 a 2019), para refinar as discussões mais } \\
\text { atuais encontradas, devido à evolução rápida das } \\
\text { TICs; } \\
\text { I4. Estudos empíricos que apresentam práticas e } \\
\text { experiências pedagógicas sobre letramento digital } \\
\text { na formação de docentes (inicial ou continuada) no }\end{array}$ & $\begin{array}{l}\text { E1. Trabalhos repetidos; } \\
\text { E2. Resultados fora do intervalo de tempo definido } \\
\text { nesta pesquisa (últimos cinco anos); } \\
\text { E3. Trabalhos que não possuem relação com o } \\
\text { tema em questão; } \\
\text { E4. Pesquisas que não são voltadas à formação } \\
\text { inicial ou continuada de docentes, i.e., voltadas } \\
\text { outras modalidades de ensino (educação básica, } \\
\text { por exemplo); } \\
\text { E5. Estudos de natureza teórica; revisão de } \\
\text { literatura; estado da arte, pesquisa bibliográfica. }\end{array}$ \\
\hline
\end{tabular}

A segunda etapa aplica o protocolo definido na etapa anterior para a identificação de estudos primários retornados após buscas nas fontes de dados; a seleção destes estudos a partir da aplicação dos critérios de inclusão e exclusão já definidos, e por fim a extração dos dados que responderão às questões de pesquisa.

Finalizada a aplicação do protocolo da pesquisa, realizou-se a análise dos dados obtidos nas duas etapas anteriores, que foram sintetizados e classificados, com dois tipos de esquemas de classificação (FELIZARDO et al., 2017, p. 104-106). A classificação independente apresenta características gerais da pesquisa, que estão presentes em muitas análise sistemáticas, que não dependem do tema em si da pesquisa; e a classificação dependente corresponde aos delineamentos organizados de acordo com as questões de pesquisa, i.e., diretamente ligadas ao tema e/ou particularidades da revisão.

\section{Resultados e Discussão}

A Tabela 1 exibe as bases de dados utilizadas e os respectivos trabalhos encontrados, a quantidade de trabalhos selecionados após a aplicação dos critérios de inclusão e exclusão, e a respectiva porcentagem de artigos incluídos em relação ao total encontrado em cada base. Foram incluídos somente oito trabalhos de um total de 85, equivalente à 9,4\% do total de trabalhos identificados nas buscas. Em relação aos tipos de publicação, foram encontrados quatro artigos, três dissertações e uma tese. Quanto à busca manual, foram realizadas buscas em dez eventos e/ou periódicos, foram encontrados cinco trabalhos. Todavia quando aplicada a segunda etapa que envolve a leitura completa do trabalho, todos foram descartados.

Tabela 1: Trabalhos encontrados/selecionados de acordo com cada base de dados. Fonte: Elaborado pelos autores (2020).

\begin{tabular}{|c|c|c|c|}
\hline Base de dados & $\begin{array}{c}\text { Trabalhos } \\
\text { encon- } \\
\text { trados }\end{array}$ & $\begin{array}{c}\text { Trabalhos } \\
\text { selecio- } \\
\text { nados }\end{array}$ & $\begin{array}{l}\text { Porcentagem } \\
\text { de artigos } \\
\text { incluídos }\end{array}$ \\
\hline Periódicos Capes (http://www.periodicos.capes.gov.br ) & 32 & 02 & $6,3 \%$ \\
\hline BDTD (http://bdtd.ibict.br/) & 35 & 04 & $11,4 \%$ \\
\hline Scielo (https://search.scielo.org/) & 13 & 02 & $15,4 \%$ \\
\hline Busca manual, em 22/05/2020 & 05 & 0 & $0 \%$ \\
\hline TOTAL & 85 & 08 & $9,4 \%$ \\
\hline
\end{tabular}

No que se refere ao procedimento de pesquisa, cinco trabalhos utilizam a observação para inferir as conclusões, que foram realizadas durante a aplicação dos momentos de práticas de ensino, que ocorreram em forma de cursos semipresencial, oficina e curso de extensão, ou simplesmente alguns encontros onde foram executadas 
IX Congresso Brasileiro de Informática na Educação (CBIE 2020)

Anais do XXXI Simpósio Brasileiro de Informática na Educação (SBIE 2020)

práticas de ensino.

Para responder a Q1, foram listadas no Quadro 2 a relação das tecnologias utilizadas nos trabalhos encontrados, divididas em tecnologias: básicas/essenciais, de comunicação, de organização/estruturação de conteúdo, Ambientes Virtuais de Aprendizagem (AVAs) e outras, que envolvem nuvens, Dispositivos Móveis Digitais (DMD) que incluem hardware e software, simuladores e enfoque em software livre.

Quadro 2: Relação das tecnologias utilizadas. Fonte: Feito pelos autores (2020).

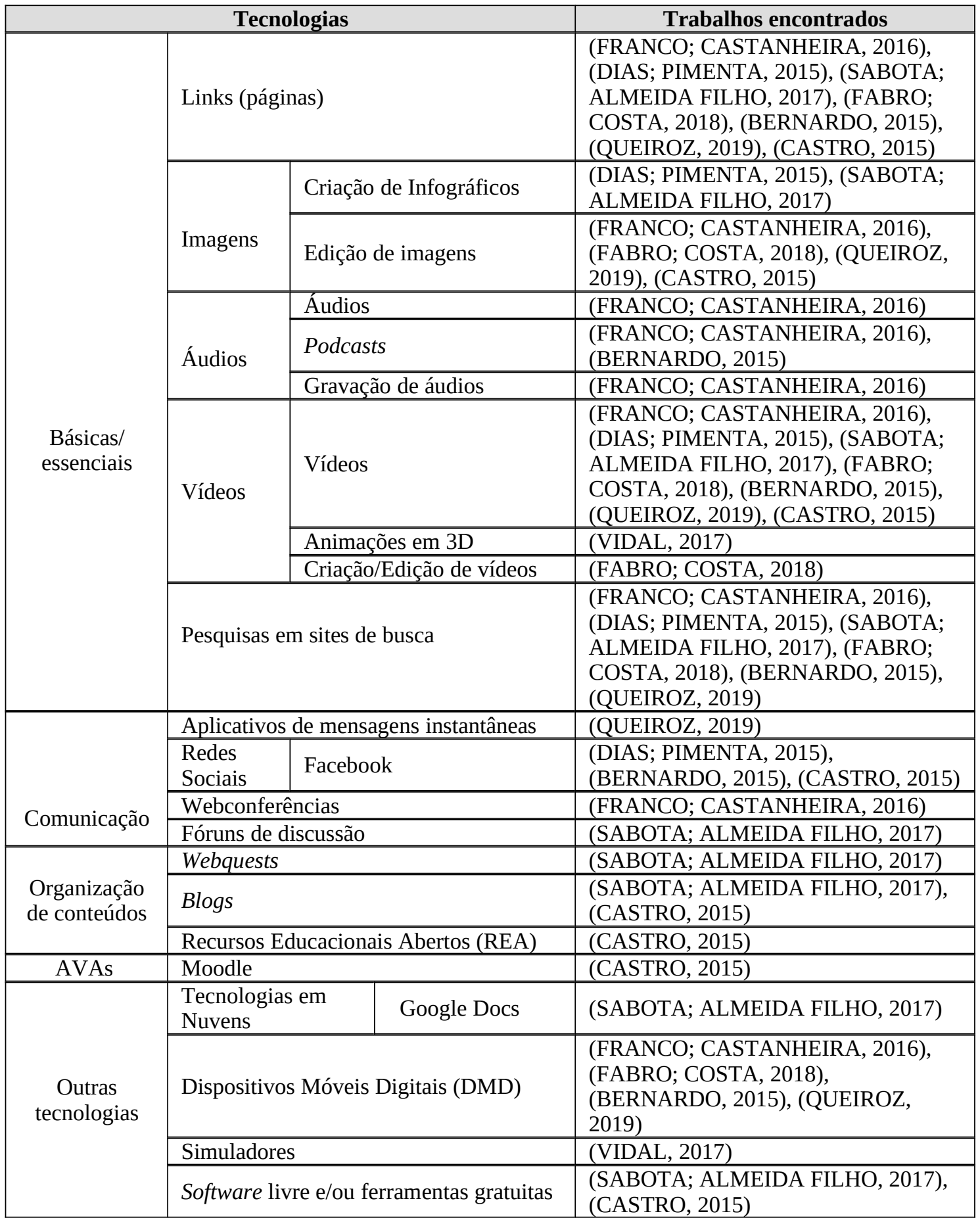


As tecnologias mais empregadas nas pesquisas foram as essenciais. Ressalta-se a diferença entre buscar/visualizar esses objetos essenciais disponíveis na Internet, outra ação é criar páginas (blogs, fóruns, etc), criar e/ou editar imagens (memes, gifs), áudios (podcasts, etc), vídeos (tutoriais, explicativos, descritivos, etc). O ambiente móvel também foi muito utilizado para comunicação, leitura, acesso e busca de informações, devido que muitas pessoas o possuem, em relação à notebooks ou tablets que nem todos possuem.

Entretanto, as menos citadas também têm sua importância e usabilidade, como por exemplo, o uso de simuladores que conseguem representar ambientes/situações reais, muitas vezes impossíveis de realizar devido à falta de infraestrutura de laboratórios e/ou insumos. As nuvens também são uma opção para compartilhamento de arquivos (sejam textos, vídeos, áudios, etc) e trabalho colaborativo entre os pares.

Sabota, Almeida Filho (2017) e Castro (2015) abordaram a importância do software livre e/ou uso de ferramentas gratuitas, que envolve a questão da liberdade e empoderamento social, forma a não se render aos padrões capitalistas e limitantes que podem convencer a pessoa que existem somente soluções pagas, sendo que existem praticamente para qualquer software soluções gratuitas para uso livre. Juntamente com a filosofia de software livre, Castro (2015) citou o uso de Recursos Educacionais Abertos (REA), que podem ser encontrados em forma de apostilas, tutoriais, vídeos, animações disponíveis para uso livre da comunidade educacional, em diversas áreas/temas e modalidades de ensino, disponibilizadas geralmente em bancos de REAs, onde a pessoa realiza buscas de recursos prontos e também pode incluir o recurso de produziu.

No que concerne às metodologias de ensino delimitadas nos trabalhos encontrados, estão relacionadas no Quadro 3, utilizado para responder a Q2. Vidal (2017) utilizou a abordagem instrucionista, onde o computador não é só uma ferramenta, mas é uma máquina de ensinar, com objetivo de resolver problemas e elaborar projetos com o uso do computador. Bernardo (2015) citou a "Pedagogia dos Multiletramentos”, definida por uma prática ensino como um processo na transformação do comportamento e formação dos indivíduos. Quatro trabalhos utilizaram Blendedlearning (B-learning, ou Ensino Híbrido), que correspondem às aulas no formato semipresencial (momentos de formação à distância e momentos presenciais), sendo que Queiroz (2019), usou a abordagem B-learning em conjunto com M-learning, modalidade de ensino que utiliza tecnologias móveis nos processos educacionais. E em outros três trabalhos as aulas ocorreram somente presenciais.

Quadro 3: Metodologias de ensino encontradas. Fonte: Autoria própria (2020).

\begin{tabular}{|l|l|}
\hline Metodologia de ensino utilizada & \multicolumn{1}{|c|}{ Trabalhos encontrados } \\
\hline \hline Abordagem instrucionista & (VIDAL, 2017) \\
\hline Pedagogia dos multiletramentos & (BERNARDO, 2015) \\
\hline Bidocência & (CASTRO, 2015) \\
\hline $\begin{array}{l}\text { Blended-learning (Ensino } \\
\text { Híbrido) }\end{array}$ & $\begin{array}{l}\text { (DIAS; PIMENTA, 2015), (FRANCO; CASTANHEIRA, 2016), } \\
\text { (SABOTA; ALMEIDA FILHO, 2017), (QUEIROZ, 2019) }\end{array}$ \\
\hline Mobile learning & (BERNARDO, 2015), (QUEIROZ, 2019) \\
\hline Aulas somente presenciais & (FABRO; COSTA, 2018), (VIDAL, 2017), (CASTRO, 2015) \\
\hline
\end{tabular}

Para responder a terceira questão desta pesquisa, o Quadro 4 lista as principais conclusões obtidas nos trabalhos selecionados. As conclusões C1 à C4, C6 à C9, C11 e C13 mostram que a incorporação e uso de tecnologias digitais na escola permite novas possibilidades para os processos educacionais. C6 e C15 denotam que o professor que é letrado digital consegue desenvolver com maior qualidade e eficiência suas atividades 
de gestão e ensino. C8 e C12 concluíram que o letramento digital contribui para a inclusão digital no ambiente escolar e também em todos os contextos sociais. C4, C5 e C9, mostraram que a união de determinadas tecnologias e metodologias de ensino contribuem para assimilação de conteúdo sobre letramento digital dos docentes em formação inicial e/ou continuada. Por fim, as conclusões C10 e C14 apresentam desafios a serem superados.

Em conclusão a esta seção, ressaltam-se as teorias encontradas nos trabalhos Sabota e Almeida Filho (2017) e Queiroz (2019), que revelam futuras pesquisas promissoras. Especificamente, Sabota e Almeida Filho (2017, p. 376), apresenta como as ferramentas digitais ajudaram na mediação do conteúdo e também a interação entre os pares. São definidas as seguintes funções: aquisição de novas informações sobre teorias e temas; compartilhamento de impressões com outros leitores (blogs, fóruns, etc); exposição de ideias presentes em textos teóricos (infográficos, por exemplo); registro de impressões sobre temas debatidos (blogs, fóruns); oportunidades de colaboração, interação, reflexão (compartilhamento de arquivos nas nuvens, grupos, webquests, etc). Essas "funções" podem auxiliar o docente a refletir sobre seu plano de ensino e definir quais ferramentas ele pode usar em suas aulas. Dessa forma, quando o docente sabe diferenciar as funções que cada ferramenta fornece, possibilidades de integração, o docente adquire autonomia e independência em seu processo de busca de informações, técnicas e conhecimentos e pode aplicar em suas aulas.

Quadro 4: Principais conclusões encontradas. Fonte: Autoria própria (2020).

\begin{tabular}{|c|c|c|}
\hline ID & Conclusões obtidas & Trabalho \\
\hline $\mathrm{C} 1$ & $\begin{array}{l}\text { B-learning foi eficaz pois estendeu a aula além do } \\
\text { momento presencial. }\end{array}$ & (FRANCO; CASTANHEIRA, 2016) \\
\hline $\mathrm{C} 2$ & B-learning forneceu tempo extra para a tarefas. & (FRANCO; CASTANHEIRA, 2016) \\
\hline C3 & $\begin{array}{l}\text { Uso de gravação de voz permitiu que o aluno ficasse } \\
\text { mais à vontade para testar seus áudios e sua pronúncia. }\end{array}$ & (FRANCO; CASTANHEIRA, 2016) \\
\hline $\mathrm{C} 4$ & $\begin{array}{l}\text { Uso de redes sociais para aprender de forma } \\
\text { colaborativa é produtivo. }\end{array}$ & (FRANCO; CASTANHEIRA, 2016) \\
\hline $\mathrm{C} 5$ & $\begin{array}{l}\text { O foco das atividades deve ser na abordagem de } \\
\text { ensino e não somente da atenção às tecnologias, e que } \\
\text { leve em conta as funções sociais da escrita. }\end{array}$ & (DIAS; PIMENTA, 2015) \\
\hline C6 & $\begin{array}{l}\text { A apropriação do uso de tecnologias leva ao docente } \\
\text { sua (re)construção crítica da identidade profissional. }\end{array}$ & $\begin{array}{l}\text { (SABOTA; ALMEIDA FILHO, } \\
\text { 2017), (CASTRO, 2015) }\end{array}$ \\
\hline $\mathrm{C} 7$ & $\begin{array}{l}\text { Tecnologias em sala de aula pode chamar a atenção } \\
\text { dos jovens alunos. }\end{array}$ & (FABRO; COSTA, 2018) \\
\hline $\mathrm{C} 8$ & $\begin{array}{l}\text { M-learning permite a liberdade de leitura e acesso à } \\
\text { informação. }\end{array}$ & (BERNARDO, 2015) \\
\hline C9 & $\begin{array}{l}\text { M-learning permite complementar o conteúdo visto } \\
\text { em sala de aula, com mídias, por exemplo. }\end{array}$ & (BERNARDO, 2015) \\
\hline C10 & $\begin{array}{l}\text { M-learning possui o desafio de maior chance de } \\
\text { desconcentração. }\end{array}$ & (BERNARDO, 2015) \\
\hline C11 & $\begin{array}{l}\text { Simulações virtuais têm grande potencial no ensino de } \\
\text { ciências. }\end{array}$ & (VIDAL, 2017) \\
\hline $\mathrm{C} 12$ & $\begin{array}{l}\text { Cibercultura permite reflexões a respeito } \\
\text { conhecimento e resolução de problemas. }\end{array}$ & (VIDAL, 2017) \\
\hline $\mathrm{C} 13$ & $\begin{array}{l}\text { É preciso despertar o interesse em inovação nos } \\
\text { docentes, para que vejam vantagem e apliquem em } \\
\text { sala de aula. }\end{array}$ & $\begin{array}{l}\text { (QUEIROZ, 2019), (CASTRO, } \\
\text { 2015) }\end{array}$ \\
\hline C14 & $\begin{array}{l}\text { Existe necessidade de reformulação dos currículos e } \\
\text { de transformação de nossas práticas pedagógicas. }\end{array}$ & (CASTRO, 2015) \\
\hline C15 & $\begin{array}{l}\text { As Tecnologias Digitais auxiliam os professores em } \\
\text { seu trabalho docente desde o planejamento até a }\end{array}$ & (CASTRO, 2015) \\
\hline
\end{tabular}


Em suma, o trabalho de Queiroz (2019), baseado no trabalho de Dias e Novais (2009), que define uma matriz modelo de letramento digital, correspondente à uma matriz de habilidades, i.e., um conjunto de competências e habilidades necessárias para resolver um problema, que no caso do letramento digital envolve habilidades técnicas e análise crítica para interagir no ciberespaço. Definem três domínios principais de aprendizagem, que com intuito de organizar as habilidades necessárias para um letrado digital, que são contato, compreensão e análise. É necessário um estudo mais aprofundando sobre esta matriz.

\section{Considerações Finais}

Em relação às metodologias de ensino, esperava-se encontrar mais experiências, relacionadas com metodologias inovadoras, tais como metodologias ativas, gamificação, Cursos Onlines Abertos e Massivos (do inglês Massive Open Online Courses MOOCs), Microlearning, etc. Além disso, percebeu-se que a maioria dos trabalhos não possuía a metodologia de ensino detalhada, atrelada com a metodologia da pesquisa, fato este que dificulta a replicação de experimentos e inferências a respeito do trabalho.

Afinal, este trabalho não conclui que existem poucas pesquisas realizadas no Brasil, pois não foram investigados bases, eventos/periódicos internacionais, onde muitas pesquisas brasileiras são publicadas. Entretanto, notou-se que existem muitas pesquisas etnográficas com o procedimento de observação para analisar se o docente ou estudante de licenciatura é considerado letrado digital. Infere-se que talvez sejam realizadas práticas, que porventura não são documentadas e publicadas para a comunidade. Portanto, urge a necessidade de que sejam publicadas mais pesquisas com foco prático, com aplicação de práticas e tecnologias relacionadas com metodologias de ensino que comprovem o sucesso ou insucesso de suas aplicações, e seus pormenores a respeito do processo de ensino-aprendizagem.

Além disso, foi perceptível nos trabalhos encontrados a falta de metodologias de ensino voltadas para adultos, i.e., baseadas em Andragogia. Vários trabalhos não selecionados tinham como público alvo alunos do ensino básico, e foi justamente por este motivo que foram retirados dessa busca, porque era almejado deparar com metodologias de ensino que atendessem às necessidades dos professores.

Também ressalta-se que não existem receitas prontas para o uso de tecnologias no letramento digital, e não foi o intento desta pesquisa encontrá-las. A finalidade foi a busca por experiências unindo metodologias de ensino e tecnologias aplicadas para formação em letramento digital para docentes, verificando o estado da arte nas pesquisas, e seus sucessos e infortúnios para que sejam engendrados novos caminhos que levem ao real aprendizado, urgente na formação inicial e continuada de educadores.

Como trabalhos futuros, vislumbram-se várias possibilidades para a continuidade desta pesquisa, dentre elas: refazer a pesquisa com o termo Andragogia e/ou termo similar; utilizar bases de artigos, eventos/periódicos internacionais; comparar a formação de letramento digital para docentes em no Brasil com outros países; estudar as diferenças na formação inicial e continuada; estudar os currículos dos cursos de licenciatura e verificar quais inserem disciplinas de uso de tecnologias nos cursos, dentre outras possibilidades. 


\section{Referências Bibliográficas}

BERNARDO, Julio Cesar Oliveira. Leitura em Dispositivos Móveis Digitais na Formação Inicial de Professores. Dissertação (Mestrado em Educação) Universidade Federal do Triângulo Mineiro (UFTM), 138 p. 2015. Disponível em: http://bdtd.uftm.edu.br/handle/tede/464. Acesso em: 22 mai. 2020.

BRASIL. [Plano Nacional de Educação (PNE)]. Plano Nacional de Educação 20142024 [recurso eletrônico] : Lei $\mathrm{n}^{\circ}$ 13.005, de 25 de junho de 2014, que aprova o Plano Nacional de Educação (PNE) e dá outras providências. - Brasília: Câmara dos Deputados, Edições Câmara, 2014. 86 p. - (Série legislação; n. 125). Disponível em: http://www.observatoriodopne.org.br/uploads/reference/file/439/documentoreferencia.pdf. Acesso em: 01 dez. 2019.

CASTRO, Wanessa de. Formação de Educadores do campo e tecnologias digitais: relações e desafios na Licenciatura em Educação do Campo da UNB. Tese (Doutorado em Educação). Universidade de Brasília (UNB), 241 p. 2015. Disponível em: http://repositorio.unb.br/handle/10482/20206. Acesso em: 22 mai. 2020.

DERMEVAL, Diego; COELHO, Jorge A. P. de M.; BITTENCOURT, Ig I. Mapeamento Sistemático e Revisão Sistemática da Literatura em Informática na Educação. In: JAQUES, Patrícia Augustin; SIQUEIRA; Sean; BITTENCOURT, Ig; PIMENTEL, Mariano. (Org.) Metodologia de Pesquisa Científica em Informática na Educação: Abordagem Quantitativa. Porto Alegre: SBC, 2020. Disponível em: https://metodologia.ceie-br.org/livro-2. Acesso em: 23 abr. 2020.

DIAS, M. C.; NOVAIS, A. E. Por uma matriz de letramento digital. In: ENCONTRO NACIONAL SOBRE HIPERTEXTO, III. Belo Horizonte, 2009. Disponível em: http://nehte.com.br/hipertexto2009/anais/p-w/por-uma-matriz.pdf. Acesso em: 10 jun. 2020.

DIAS, Reinildes; PIMENTA, Sônia Maria de Oliveira. Technologies, literacies in English oral communication and teacher education: an empirical study at the university level. Rev. bras linguist. apl., Sept 2015, vol.15, no.3, p.711-733. Disponível em: https://www.scielo.br/scielo.php?script=sci arttext\&pid=S198463982015000300711. Acesso em: 22 mai. 2020.

FABRO, Maria de Lourdes Sousa; COSTA, Thérèse Hofmann Gatti Rodrigues da. Projeto Anima Barretos: Tecnologia, Educação e Mediação Cultural. Matéria-Prima, Faculdade de Belas-Artes da Universidade de Lisboa, 2018, v. 6, n. 3, p. 183-193. Disponível em: https://repositorio.ul.pt/bitstream/10451/38013/2/ULFBA MP v6 iss3 p183-193.pdf. Acesso em: 22 mai. 2020.

FELIZARDO, K. et. al. Revisão Sistemática da Literatura em Engenharia de Software. 1 ed. Rio de Janeiro: Elsevier, 2017.

FRANCO, Raquel Aparecida Soares Reis; CASTANHEIRA, Maria Lúcia. Práticas de Letramento Acadêmico no Facebook. Ilha Desterro, Dez 2016, vol.69, no.3, p.13-28. Disponível em: https://www.scielo.br/scielo.php?pid=S217580262016000300013\&script=sci abstract\&tlng=pt. Acesso em: 22 mai. 2020.

KITCHENHAM, Barbara. A.; CHARTERS, Stuart. Guidelines for performing Systematic Literature Reviews in Software Engineering. Version 2.3, Keele: Staffs-UK and Durham-UK. 2007. 
MOURA, Késsia Mileny de Paulo. Revisão sistemática sobre letramento digital na formação de professores. Texto Livre: Linguagem e Tecnologia, [S.l.], v. 12, n. 3, p. 128-143, set. 2019. Disponível em: http://www.periodicos.letras.ufmg.br /index.php/textolivre/article/view/15167. Acesso em: 01 mai. 2020.

MOURA, Késsia de Paulo; CARVALHO, Marie Jane Soares; MION, Mirian. O LETRAMENTO DIGITAL NA FORMAÇÃO DE PROFESSORES: uma revisão sistemática das produções. In Anais do XXX Simpósio Brasileiro de Informática na Educação (SBIE 2019). p. 606-615. Brasília-DF: nov. 2019. Disponível em: https://br-ie.org/pub/index.php/sbie. Acesso em: 01 mai. 2020.

PINTO, Joane Vilela; BOSCARIOLI, Clodis; CAPELLI, Claudia. Letramento digital: uma revisão sistemática sobre o conceito para aplicação na área da educação. Revista Tecnologias na Educação. Ano 10. num/vol 28. dez. 2018. Disponível em: https://tecedu.pro.br/wp-content/uploads/2019/01/Art19-Ano-10-vol28-Dezembro2018.pdf. Acesso em: 01 mai. 2020.

QUEIROZ, Camila Vilela de. Adoção da inovação, letramento digital e docência: o uso de dispositivos e aplicativos móveis no contexto de formação continuada. Dissertação (Mestrado em Linguística Aplicada). Universidade Federal de Minas Gerais (UFMG), p. 104. 2019. Disponível em: http://hdl.handle.net/1843/LETRBALJKT. Acesso em: 22 mai. 2020.

SABOTA, Barbra; ALMEIDA FILHO, José Carlos Paes de Almeida. Análise do potencial da mediação tecnológica para o enriquecimento da competência teórica de professores de línguas. Acta Scientiarum. Language and Culture (UEM), Universidade Estadual de Maringá, Out-Dez-2017, v. 39, n. 4, p. 369-380. Disponível em: http://periodicos.uem.br/ojs/index.php/ActaSciLangCult/article/view/ 31594/pdf. Acesso em: 22 mai. 2020.

VALENTE, José Armando. As tecnologias digitais e os diferentes letramentos. Pátio. Revista Pedagógica (Porto Alegre), v. 11, p. 12-15, 2007.

VIDAL, Natália Ferreira. O uso de simulações virtuais em oficinas de formação para professores de ciências da educação básica. Dissertação (Mestrado em Educação). Universidade Federal de Juiz de Fora (UFJF), 107 p. 2017. Disponível em: http://repositorio.ufjf.br:8080/jspui/handle/ufjf/6521. Acesso em: 22 mai. 2020.

WILSON, Carolyn et. al. Alfabetização midiática e informacional: currículo para formação de professores. Brasília: UNESCO, UFTM, 2013. 194 p. Disponível em: http://www.unesco.org/new/pt/brasilia/communication-and-informatio/. Acesso em: 01 dez. 2019. 